\title{
Percepção da qualidade de vida no trabalho dos neurocirurgiões em São Paulo
}

\author{
Sandra Arcelina da Silva', Ramon Barbalho Guerreiro², Marise \\ Augusto Fernandes Audi ${ }^{3}$, Fernanda Fernandes Audi, Yuri dos Santos \\ Buscariolli5 , José Marcus Rotta ${ }^{6}$, Ricardo Vieira Botelho
}

Programa de Pós-Graduação em Ciências da Saúde do Instituto de Assistência Médica do Servidor Público do Estado (IAMSPE), São Paulo, SP.

\section{RESUMO}

Contexto: Estudos da percepção da qualidade de vida no trabalho (QVT) permitem estimar a percepção de uma classe profissional inteira, identificar desequilíbrios específicos e proporcionar políticas de desenvolvimento profissional. Objetivo: Avaliar a percepção da QVT dos neurocirurgiões que trabalham em Serviços de Emergência em São Paulo usando instrumentos de validação disponíveis na língua portuguesa. Método: A percepção da QVT dos neurocirurgiões da cidade de São Paulo (Capital) foi estudada com questionário validado para língua portuguesa. Resultados: Cinquenta e oito neurocirurgiões responderam ao questionário. A análise revelou fortes tendências negativas na maioria das áreas de QVT. As áreas com forte tendência negativa deveriam ser tratadas com políticas específicas. Conclusão: Há fortes tendências negativas em quase todos os domínios da QVT.

\section{PALAVRAS-CHAVE}

Qualidade de vida, ambiente de trabalho, carga de trabalho, condições de trabalho, neurocirurgiões.

\begin{abstract}
Perception on quality of life at work by neurosurgeons in São Paulo

Context: Studies of the perception of quality of work life (QWL) allow estimating the perception of an entire professional class, identifying specific imbalances and provide professional development policies. Objective: To evaluate the perception of QWL of neurosurgeons working in Emergency Services in São Paulo, using available validated instrument in Portuguese language. Method: The city of São Paulo (Capital) was defined as the geographical area to be studied with a validated questionnaire. Results: Fifty-eight neurosurgeons answered the QWL questionnaire revealing strong negative trends in most areas of QWL. These responses can be compared across institutions and over different periods of time, potentially allowing the identification of locations with more suitable development areas related to QWL. To improve the perception of QWL means, areas with strong negative trend should be treated with specific policies. Conclusion: There is strong negative trends in almost all areas of QWL.
\end{abstract}

\section{KEYWORDS}

Quality of life, job satisfaction, occupational health, work load, neurosurgeons.

\section{Introdução}

A expectativa de vida ao nascer tem aumentado, passando dos 70 anos em 1998 para, praticamente, 73 anos em 2008. ${ }^{3}$ Paralelamente à expectativa de vida, a qualidade de vida tem sido utilizada para estudar grupos-alvo ou populações inteiras.

O trabalho ocupa a maior parte do tempo de uma pessoa e é o principal organizador da vida humana. ${ }^{8}$

1. Assistente social do Hospital do Servidor Público do Estado (HSPE), Instituto de Assistência Médica do Servidor Público do Estado (IAMSPE), São Paulo.

2. Médico neurocirurgião do HSPE, IAMSPE, São Paulo.

3. Médica neurocirurgiã do Hospital Edmundo Vasconcelos.

4. Estudante de Medicina do Centro Universitário Lusíada (Unilus), Santos, SP.

5. Estudante de Medicina da Universidade Cidade de São Paulo (Unicid), SP.

6. Diretor do Serviço de Neurocirurgia do HSPE, IAMSPE, São Paulo, presidente da Sociedade Brasileira de Neurocirurgia.

7. Médico neurocirurgião, doutorado e pós-doutorado em Ciências pelo Departamento de Psicobiologia da Universidade Federal de São Paulo (Unifesp), orientador do Programa de Pós-graduação em Ciências da Saúde, IAMSPE, São Paulo. 
Os estudos das características que compõem a qualidade de vida relacionada ao trabalho (QVT) atualmente podem ser realizados com o uso de instrumentos adequados, mas não têm sido feitos em médicos. Esse estudo possibilitaria estimar a percepção relacionada aos seus locais de trabalho, identificando desajustes específicos e possibilitando programar políticas de valorização profissional. Um instrumento de avaliação da percepção da QVT seria uma ferramenta de diagnóstico para o sistema de atenção à saúde.

O objetivo deste trabalho foi o de avaliar a percepção da QVT dos médicos neurocirurgiões dos serviços de emergência da cidade de São Paulo utilizando instrumento validado em língua portuguesa.

\section{Métodos}

Foi definida a área geográfica determinada para estudo como o município de São Paulo (capital). Os neurocirurgiões foram descritos por idade, gênero e estado civil. Foram avaliados os tempos após a formatura (tempo de formado) e após o término da residência (tempo de especialidade), o período de trabalho (noturno, diurno e ambos) e o tempo trabalhado por plantão. Inicialmente, foram identificados os Serviços de Emergência que atendiam neurocirurgia e, a partir deles, identificados os neurocirurgiões desses Serviços.

A identificação dos Serviços de Neurocirurgia de Emergência foi feita por pesquisa eletrônica no site da Secretaria Municipal de Saúde e foi feita uma busca no banco de registros da Associação de Neurocirurgiões do Estado de São Paulo. A lista dos neurocirurgiões foi obtida pelas secretarias dos respectivos Serviços de Neurocirurgia, com a autorização expressa dos seus diretores. Apenas os Serviços nos quais se conseguiu essa autorização foram avaliados. O questionário foi entregue em mãos ao neurocirurgião.

\section{Escolha do método de quantificação da QVT}

Foram pesquisados os questionários disponíveis que pudessem ser aplicáveis aos profissionais objeto do estudo. A avaliação da literatura revelou que os critérios de Walton são os critérios classicamente usados. ${ }^{9,10,12}$ Eles subdividem a QVT em oito domínios: 1) compensação justa e adequada; 2) condições de trabalho; 3 ) uso e desenvolvimento de capacidades; 4 ) oportunidade de crescimento e segurança; 5) integração social na orga- nização; 6) constitucionalismo; 7) o trabalho e o espaço total de vida; 8) relevância social do trabalho na vida.

A segunda etapa da pesquisa consistiu em identificar um questionário que utilizasse os critérios de Walton e que tivesse sido validado em língua portuguesa no Brasil. Foram comparados os questionários frequentemente citados na literatura. O questionário de Ritz ${ }^{7}$ (Tabela 1) foi considerado adequado. Ele é composto por 54 afirmações que abrangem os critérios de Walton. Para avaliação final, as afirmações foram reagrupadas segundo os domínios e descritas como percentagem da amostra de neurocirurgiões que concorda, discorda ou se mantém neutro ou indiferente (Tabela 1).

O agrupamento das afirmações de Ritz segundo os critérios de Walton está demonstrado nas figuras 1 e 2 e na tabela 1 .

Os serviços de emergência cujos neurocirurgiões fizeram parte da pesquisa foram:

- Zona Central:Hospital do Servidor Público Municipal;

- Zona Leste: Hospital Municipal Prof. Dr. Alípio Correa Netto - Ermelino Matarazzo; Hospital Municipal Dr. Carmino Caricchio - Tatuapé; Hospital Santa Marcelina;

- Zona Norte: Hospital do Mandaqui;

- Zona Oeste: Santa Casa de Misericórdia de São Paulo;

- Zona Sul: Hospital do Servidor Público Estadual (HSPE); Hospital Municipal Dr. Arthur Ribeiro Saboya - Jabaquara; Hospital Municipal Dr. Fernando Mauro Pires da Rocha - Campo Limpo; Hospital Ipiranga; Hospital Regional Sul.

\section{Resultados}

\section{Caracterização da população do estudo}

Entre novembro de 2007 e setembro de 2008, 58 neurocirurgiões foram convidados a participar da pesquisa respondendo ao questionário. Apenas um respondeu parcialmente, não respondendo às perguntas que considerava pessoais, e outro respondeu parcialmente às afirmações. Os demais 56 responderam completamente ao questionário.

\section{Dados antropométricos e característica do trabalho}

Idade, gênero e estado civil: a média etária foi de $41,42 \pm 9$ (IC 95\% = 39-44); a idade mais frequentemente encontrada foi de 32 anos (variando entre 29 e 60 anos); $45(73 \%)$ do gênero masculino e 12 (27\%) do feminino. 
Tabela 1 - Resultados da percepção da QVT segundo os oito domínios de Walton e afirmações de Ritz

Afirmação

1 - Domínio - Compensação Justa e Adequada

1. O salário é suficiente para o sustento da família.

10. O salário é compatível com as funções que exercem.

19. O salário é defasado em relação ao mercado.

28. Ser pago adequadamente em comparação com os colegas.

37. O salário está de acordo com a importância do trabalho.

46. Meu trabalho me proporciona um bom padrão de vida.

2 - Domínio condições de trabalho

2. Sinto-me seguro no ambiente de trabalho.

11. Tenho à disposição EPIs necessários.

20. A minha área de trabalho não é insalubre.

29. Estou satisfeito com o espaço e a disposição do lugar onde desenvolvo meu trabalho.

38. A empresa oferece assistência médica adequada.

47. A empresa se preocupa com a minha saúde (exame periódico etc.).

3 - Domínio - Uso e desenvolvimento de capacidades

3. Tenho informações significativas sobre o processo total de trabalho.

9. Faço meu trabalho sempre de maneira diferente

12. Recebo as informações de que necessito para desempenhar bem o meu trabalho.

18. Sou reconhecido pela contribuição das minhas atividades para os resultados alcançados pela empresa.

21. O nível de treinamento recebido para desempenho com eficiência

e segurança das tarefas atribuídas é satisfatório.

27. Minha opinião é solicitada para organização do trabalho em minha área.

30. Acho importante minhas tarefas no conjunto de operações da área.

36. Estou de acordo com o planejamento e a organização das atividades da área.

39. Tenho feedback a respeito do meu trabalho.

45. Quando minha chefia toma decisões e se compromete envolvendo meu trabalho,

isso é feito com minha participação por meio de troca de ideias.

48. Todas as vezes em que as mudanças vão afetar o meu trabalho,

minha chefia procura saber a minha opinião.

54. Discuto métodos de trabalho com os participantes da minha área.

4 - Domínio - Oportunidade de crescimento e segurança

4. Minha atividade contribui para manter e expandir minha capacidade.

13. Minha atividade não favorece meu crescimento profissional.

22. Tenho garantia de um salário associado com meu trabalho.

31. Há preocupação contínua por parte de minha chefia em fazer uso total das minhas habilidades.

40. A empresa estimula seus funcionários a se desenvolverem como pessoas.

49. As promoções são baseadas na competência.

5 - Domínio - Integração social na organização

24. Sou tratado de maneira igual aos meus colegas de trabalho em todos os assuntos.

6. Tenho que dar satisfação à minha chefia no que se refere ao meu comportamento

fora do horário de trabalho ou sobre atos dos membros de minha família.

15. Tenho direito de discordar da visão dos meus superiores, sem medo de represálias.

33. Minha chefia recebe bem minhas ideias mesmo quando elas diferem das suas.

42. Sigo as normas de disciplina dentro da minha área.

50. Colaboro com meus colegas no desempenho das suas funções.

6 - Domínio - Constitucionalismo

6. Tenho que dar satisfação à minha chefia no que se refere ao meu comportamento

fora do horário de trabalho ou sobre atos dos membros de minha família.

15. Tenho direito de discordar da visão dos meus superiores, sem medo de represálias.

33. Minha chefia recebe bem minhas ideias mesmo quando elas diferem das suas.

42. Sigo as normas de disciplina dentro da minha área.

47. A empresa se preocupa com a minha saúde (exame periódico etc.),

51. Conheço as normas internas de segurança no trabalho.

7 - Domínio - O trabalho e o espaço total de vida

7. Minha jornada de trabalho está de acordo com minha função.

16. A jornada era compatível com a remuneração.

25. Meu horário de trabalho não toma meu tempo de descanso e o tempo com a minha família.

34. Considero o período de almoço adequado.

43. O tempo de intervalo ( 5 minutos) durante a jornada de trabalho é suficiente.

52. O trabalho me afasta de minha família.

8 - Domínio - Relevância social do trabalho na vida

8. Percebo a minha empresa responsável socialmente, por exemplo, em seus produtos.

17. A minha empresa estimula trabalho voluntário durante o horário de trabalho.

26. Vejo a minha empresa tendo ações no sentido de proteger o meio ambiente.

35. Minha empresa mostra-se preocupada com a comunidade.

44. Minha empresa tem atitudes no que se refere a proteger o meio ambiente do seu lixo industrial.

53. Minha empresa acha que proteger o meio ambiente é responsabilidade somente da comunidade
Concordam (\%) Discordam (\%)

Neutros ou

indecisos $(\%)$

18

9

80

48

9

35

32

7

16

5

4

\begin{tabular}{ccc}
40 & 53 & 7 \\
17 & 66 & 17 \\
8 & 66 & 26 \\
28 & 51 & 21 \\
25 & 38 & 37 \\
17 & 29 & 54 \\
\hline
\end{tabular}




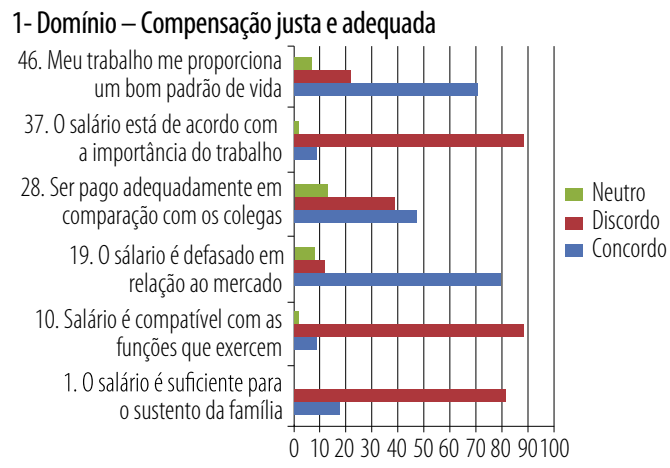

3- Domínio - Uso e desenvolvimento de capacidades

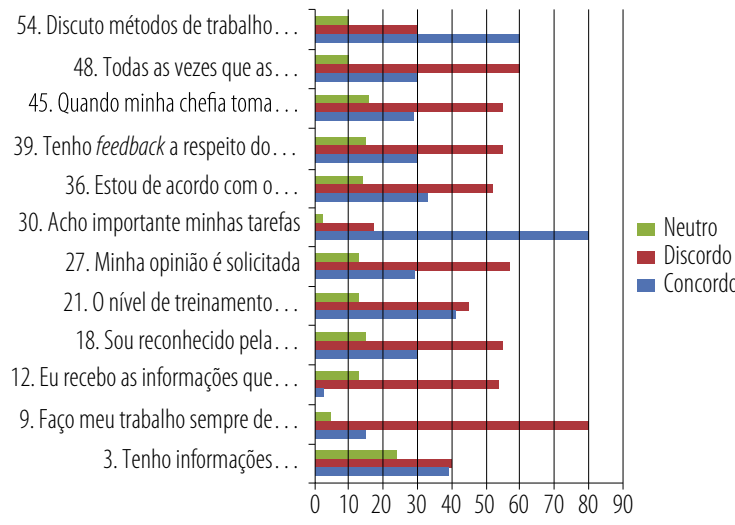

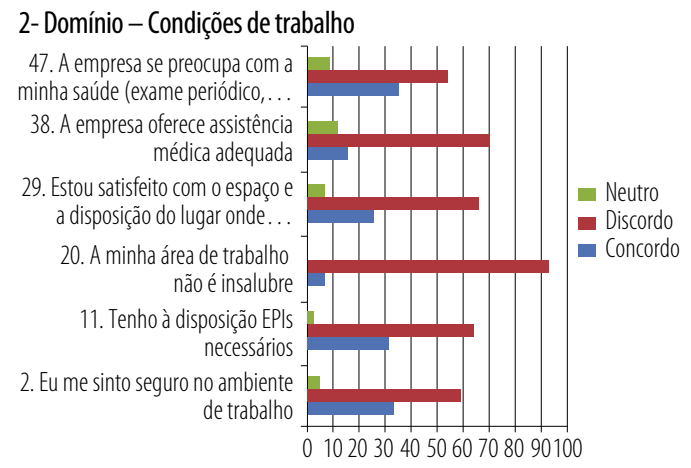

4- Domínio - Integração social na organização

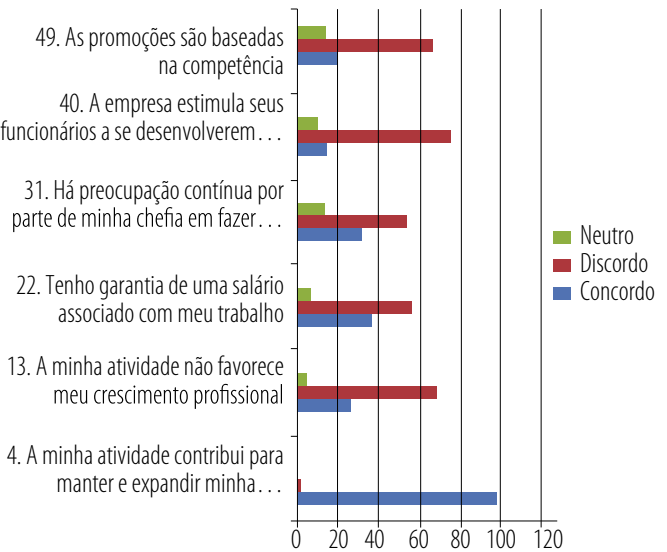

Figura 1 - Distribuições das afirmações de Ritz segundo os domínios 1 a 4 de Walton, com suas respectivas respostas pelos neurocirurgiões.

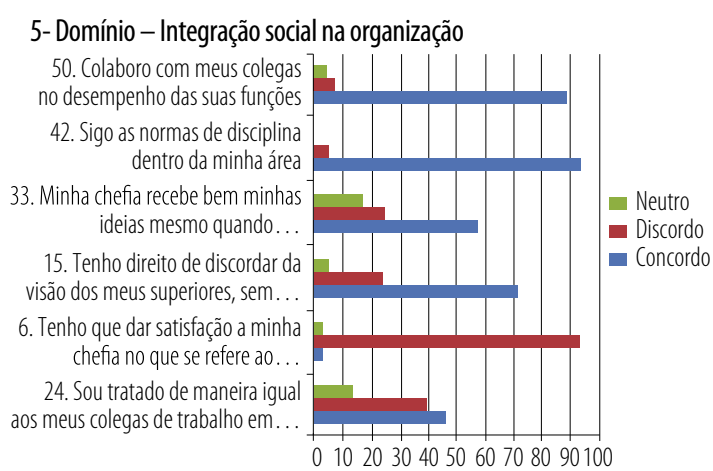

7- Domínio - 0 trabalho e o espaço total de vida

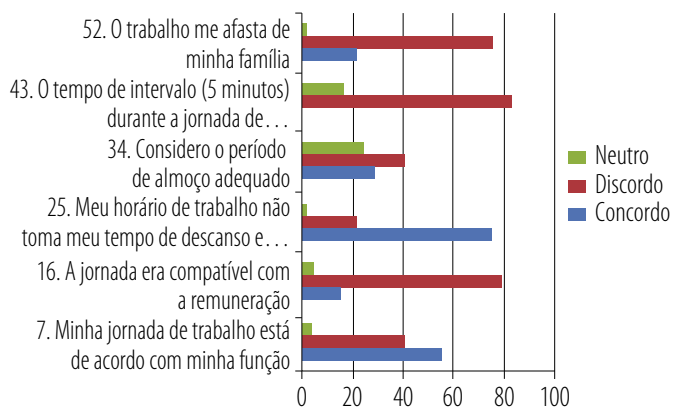

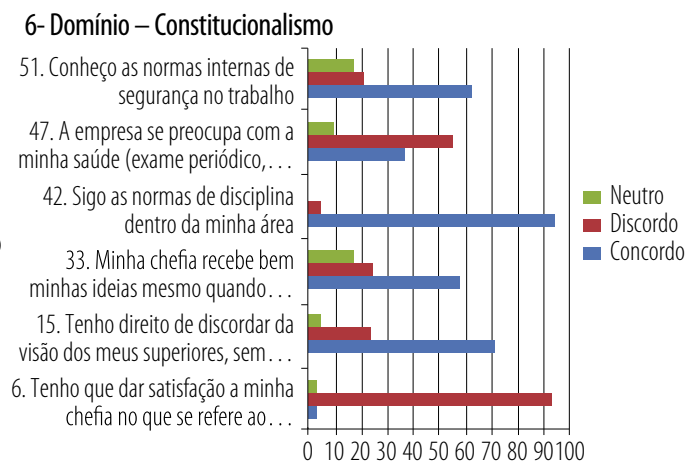

8- Domínio - Relevância social do trabalho na vida

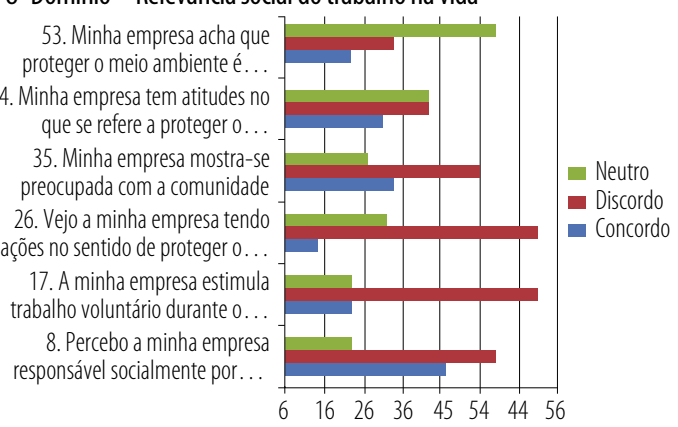

Figura 2 - Distribuições das afirmações de Ritz segundo os domínios 5 a 8 de Walton com suas respectivas respostas pelos neurocirurgiões. 
Trinta e oito declararam-se casados, 15 solteiros e 4 divorciados ou separados, e um não respondeu.

Tempos de formado e tempo de especialidade: $\mathrm{O}$ tempo de formado foi de $17 \pm 9$ anos (IC 95\% = 14,619,4 - variando entre 5 e 35 anos). O tempo como especialista foi de $11 \pm 8,54$ anos (IC 95\% = 8,7-13,30).

Período de trabalho: 10 trabalhavam no período diurno, 6 trabalhavam no período noturno e 41 trabalhavam em ambos os períodos, 5 trabalhavam em dois plantões em hospitais diferentes.

Média de horas trabalhadas por plantão: a média de horas trabalhadas por plantão foi de 20,6 \pm 5 horas (IC 95\% = 19-22). Trinta e dois trabalhavam 24 horas semanais em plantões.

Resultados da percepção da QVT: o resultado foi disposto segundo os domínios da QVT. As afirmações foram agrupadas considerando as respostas como concordo, discordo e neutro, detalhando melhor a convicção de resposta do respondedor.

As respostas a seguir foram descritas para aquelas cujos resultados obtiveram maioria simples dos respondedores (>50\%), sendo considerados resultados fortemente negativos ou positivos. Os detalhes de respostas estão disponíveis na tabela 1 e nas figuras 1 e 2 .

No domínio 1, compensação justa e adequada, os neurocirurgiões, na sua maioria, discordam que o salário está de acordo com a importância do trabalho, que está compatível com a função que exercem e que é suficiente para o sustento da família. A maioria concorda ser paga adequadamente em comparação com os colegas e que o salário está defasado em relação ao mercado. Todas essas respostas foram resultados fortemente negativos. Eles consideram que seu trabalho proporciona um bom padrão de vida e que os colegas são pagos com equidade.

No domínio 2, condições de trabalho, a maioria discorda que a empresa se preocupa com a sua saúde e oferece assistência médica adequada, que esteja satisfeito com o espaço e o lugar do trabalho, que a atividade não seja insalubre, que tenha acesso aos equipamentos individuais de proteção necessários e que se sentem seguros no ambiente de trabalho. Todas as respostas foram fortemente negativas.

No domínio 3, uso e desenvolvimento de capacidades, a maioria acha importante suas tarefas no conjunto de operações da área e discute métodos de trabalho com os participantes da área. A maioria discorda que sua chefia procura saber sua opinião quando as mudanças vão afetar seu trabalho ou que ela toma decisões com participação e troca de ideias, bem como discorda do planejamento e da organização das atividades da área, que sua opinião seja solicitada para organização do trabalho da área, que recebe as informações de que necessita para desempenhar bem o trabalho, que é reconhecido pela contribuição das suas atividades para os resultados alcançados pela empresa e que faz seu trabalho sempre de maneira diferente.

No domínio 4, oportunidade de crescimento e segurança, a maioria concorda que a atividade contribui para manter e expandir sua capacidade. A maioria discorda que sua atividade não favorece o crescimento profissional, que tem garantia de um salário associado com seu trabalho, que há preocupação contínua por parte da chefia em fazer uso total das suas habilidades, que a empresa estimula seus funcionários a se desenvolverem como pessoas e que as promoções são baseadas na competência.

No domínio 5, integração social na organização, os neurocirurgiões concordam que têm o direito de discordar da visão dos seus superiores, sem medo de represálias, que sua chefia recebe bem suas ideias mesmo quando elas diferem das dela, que seguem as normas de disciplina dentro da área e que colaboram com os colegas no desempenho das funções.

No domínio 6, constitucionalismo, a maioria concorda que segue as normas de disciplina. A maioria concorda que tem direito de discordar da visão dos seus superiores, sem medo de represálias, que sua chefia recebe bem suas ideias, mesmo quando elas diferem das dela, que segue as normas de disciplina dentro da sua área, que conhece as normas internas de segurança no trabalho. Os pesquisados discordam que tenham que dar satisfação à chefia no que se refere ao seu comportamento fora do horário de trabalho ou sobre atos dos membros de sua família e discordam que a empresa se preocupa com a sua saúde.

No domínio 7, o trabalho e o espaço total de vida, a maioria concorda que sua jornada de trabalho está de acordo com sua função e que seu horário de trabalho não toma seu tempo de descanso e o tempo com sua família. A maioria discorda que a jornada é compatível com a remuneração, que o intervalo durante a jornada é suficiente e que o trabalho o afasta de sua família.

No domínio 8 , relevância social do trabalho na vida, a maioria foi neutra ou indecisa em afirmar que a empresa acha que proteger o meio ambiente é responsabilidade da comunidade. A maioria discorda em ver a empresa com atitudes para proteção no meio ambiente. A maioria não percebe a empresa como responsável socialmente, não considera que a empresa estimula trabalho voluntário durante o horário de trabalho, não vê a empresa desenvolvendo ações no sentido de proteger o meio ambiente e não concorda que a empresa se mostra preocupada com a comunidade. Neste domínio, houve uma afirmação (53) cuja maioria das respostas foi neutra ou indecisa: "Minha empresa acha que proteger o ambiente é somente responsabilidade da comunidade". Uma resposta cuja maioria seja neutra provavelmente não é relevante para a classe estudada. 


\section{Discussão}

O conceito de qualidade de vida se consolidou a partir da década de 1960, quando passou a ser empregado como contraponto às avaliações estritamente econômicas do nível de desenvolvimento dos países. ${ }^{2,11,12}$ A qualidade de vida relacionada ao trabalho tem recebido atenção a partir de 1959.4,6

A transformação do ambiente de trabalho num local sadio pode proporcionar maior satisfação na execução das atividades profissionais, bem como, numa situação contrária, pode desencadear o mau desempenho das funções. ${ }^{6} \mathrm{~A}$ avaliação da percepção da qualidade de vida no trabalho possibilita o entendimento das relações do profissional com seu meio de trabalho, a percepção da valorização de sua unidade perante o mesmo profissional e como ele a considera com relação à sociedade, sua relativa posição de valorização pela unidade, sua inserção na tomada de decisões, sua participação na administração e nas mudanças administrativas que modificam seu trabalho, além de sua valorização financeira no trabalho. Permite também verificar qual a intensidade de afastamento familiar o trabalho condiciona. Essas avaliações podem ser confrontadas entre instituições, municípios, estados e, eventualmente, países e pode ser feita a comparação entre épocas diferentes.

O Jornal da Associação Médica Brasileira de julho/ agosto de 2010 relata que, entre as razões para a distribuição iníqua dos profissionais de saúde no Brasil, predomina "a péssima qualidade do ambiente de trabalho, prejudicando o desempenho e afastando dele os profissionais". É necessário transformar o ambiente de trabalho de sorte a atrair e fixar aqueles que trabalham com saúde, melhorando a satisfação e o resultado da assistência às pessoas. ${ }^{1}$ Embora várias profissões e mesmo nações tenham incorporado o conceito da QVT em suas avaliações, a classe médica e os neurocirurgiões não têm sido muito avaliados.

O questionário a ser usado deveria analisar valores em conflito nas transformações que ocorrem na saúde, contrastando conceitos de produtividade e avanço tecnológico com satisfação profissional. Os critérios de Walton são os mais citados na literatura. ${ }^{7,9,10,12} \mathrm{O}$ questionário de Ritz ${ }^{7}$ possibilitou avaliar as categorias conceituais de Walton em 54 afirmações aleatoriamente distribuídas. As afirmações foram classificadas de acordo com uma escala Likert, de acordo com sua concordância. ${ }^{5}$ Este estudo é uma aplicação de questionário validado para uso em enfermeiras. Os autores e a classe profissional estudada consideraram-no adequado para essa avaliação. Apenas a afirmação 53 necessita ser avaliada em trabalhos futuros, pois obteve maioria de respostas neutras ou indecisas.

A maioria dos neurocirurgiões não considera estar recebendo uma compensação justa de acordo com a importância de seu trabalho e sua carga de trabalho, não está satisfeita com as condições de trabalho, não confia na sinceridade e honestidade da alta cúpula administrativa de sua empresa e não participa das mudanças que ocorrem em seu trabalho. A avaliação revelou fortes tendências negativas na maioria dos domínios da QVT. Essas respostas poderão ser comparadas entre instituições e em períodos diferentes de tempo, potencialmente permitindo a identificação de locais com mais adequado desenvolvimento dos domínios relativos à QVT aos neurocirurgiões. A melhoria da percepção da QVT implica que sejam tratados os domínios de forte tendência negativa com políticas adequadas e reforçadas as tendências positivas.

\section{Referências}

1. Amaral JLG, Lopes MGD. A qualificação do ambiente de trabalho. JAMB. 2010. Disponível em http://www.amb.org. br/teste/imprensa/jamb/jamb_2010_jul_ago.pdf.

2. Felce D. Defining and applying the concept of quality of life. J Intellect Disabil Res. 1997;41:99-199.

3. Instituto Brasileiro de Geografia e Estatística - Projeção da População Brasileira por Sexo e Idade - 1980-2050 [Estudo Epidemiológico]. Disponível em: http://www.ibge.gov.br/ home/estatistica/populacao/projecao_da_populacao/2008/ metodologia.pdf.

4. Lawler III E, Porter L. Managers pay and their satisfaction with their pay. Personnel Psychol. 1966;19:363-73.

5. Likert R. A technique for the measurement of attitudes. Arch Psychol. 1932;140:1-55.

6. Nadler LA. Supervisor supervises people, not jobs. Mod Hosp. 1959;92:61-6.

7. Ritz MRC. Qualidade de vida no trabalho: construindo, medindo e validando uma pesquisa [dissertação]. Campinas: Universidade de Campinas; 2000.

8. Aposentadoria: período de transformações e preparação. Disponível em: http://www.utfpr.edu.br/pontagrossa/ estrutura-universitaria/diretorias/dippg/mestrado/ppgep/ publicacoes/2004. Acessado em 21 mar. 2011.

9. Timossi LS. Correlações entre a qualidade de vida e a qualidade de vida no trabalho em colaboradores das indústrias de laticínios [dissertação]. Ponta Grossa, PR: Universidade Tecnológica Federal do Paraná; 2009.

10. Trierweiler M, Silva N. Perspectivas e desafios para a gestão da qualidade de vida nas organizações de trabalho. Estud Psicol. 2007;12:185-6.

11. Vasconcelos AF. Qualidade de vida no trabalho: origem, evolução e perspectivas. Caderno de Pesquisas em Administração. 2001;8:23-35.

12. Walton R. Quality of working life: what is it? Slow Management Review. 1973;15:11-21.

Endereço para correspondência

Ricardo Vieira Botelho

Rua Dr. Altino Arantes, 390, ap. 81, Vila Clementino

04042-002 - São Paulo, SP, Brasil

Telefax: (11) 5088-8379

E-mail: bitbot@uol.com.br 